\title{
Experimental Investigation on Weld Ability of Cast Iron
}

\author{
Alie Wube Dametew \\ Department of Mechanical Engineering, Research and technology Transfer Head, KIOT Wollo University, Dessie, Ethiopia
}

Email address:

wubealie@gmail.com, alie20123@gmail.com

\section{To cite this article:}

Alie Wube Dametew. IExperimental Investigation on Weld Ability of Cast Iron. Science Discovery. Vol. 3, No. 6, 2015, pp. 71-75. doi: $10.11648 /$ j.sd.20150306.15

\begin{abstract}
Welding cast iron is used in ships, bridges, pressure vessels, industrial machinery, automobile, rolling stock and many other fields. Problems associated with welding are common issues in these fields. A Study was conducted to investigate Weldability of grey cast iron, as grey cast iron contains graphite in flake form, carbon can readily be introduced into the weld pool, causing weld metal embrittlement and Grey cast iron welds are subject to the formation of porosity and the cold cracking susceptibility of welds. When we observed that gray cast iron is welded non uniform heating and cooling in weld metal and in base metal generates harder Heat Affected Zone (HAZ), cold crack susceptibility and residual stress in weldement. Different methods investigate experimentally to minimize above difficulties. Those methods for reducing the effects of above problems were, minimize base metal dilution, compensate for shrinkage stresses, and the use of low strength filler metals to reduce cracking without sacrificing overall joint strength. Main while the beast type of arc welding electrodes for welding of grey cast iron are nickel and nickel-iron types have been used with or without preheating and / or post weld heat treatment. At the same time Cast iron and steel electrodes must be used with high preheats $\left(530^{\circ} \mathrm{C}\right)$ to prevent cracking and the formation of hard deposits. The other mechanisms to improve Weldability of gray cast iron are Pre heating and/or Post heating of the base metal was experimentally employed and investigated.
\end{abstract}

Keywords: Weldability, Cast Iron, Experiment Investigation, Improvement, Welding Factor

\section{Introduction}

Welding is currently used for fabrication and construction of a variety of structures such as buildings, bridges, ships, offshore structures, boilers, storage tanks, pressure vessels, pipelines, automobiles and rolling stock. These structures use various types of steels and cast irons suitable for their specific applications. Different metals inherently possess different weld ability. Some metals are readily wieldable, but some are difficult to weld like cast iron.( KitaShinagawa,2011, Arc Welding of Specific Steels and Cast Irons). Cast iron is a generic term describing a variety of iron-base alloys containing $1.7 \%$ to $4.5 \%$ carbon. The high carbon content of cast iron increases welding difficulty compared to welding steels which possess lower carbon content.

The most common cast irons are the gray irons although malleable and nodular types are often encountered. Malleable and nodular cast iron offer more ductility than gray iron since they include a round graphite structure whereas gray iron contains graphite in flake form which results in brittleness. Because welding on these cast irons does create undesirable metallurgicalchanges in the heat-affected zone, every procedure imaginable has been written for cast iron welding ( AMPCO Metal Excellence in engineering Alloys). The differential gear is a functional component of the automobile power train and is composed of the differential case and ring gear.

Differential gear compensates the trace difference between in-corner wheel and out-corner wheel, while an automobile turns a corner, and enables normal driving. The power train of the automobile delivers engine power to the automobile wheel. Due to this property, it should have good tensional stiffness, wear resistance and fatigue strength.( KitaShinagawa, 2011)

Carburized steel is also used for the ring gear of a power train. However, since these two base materials contain high carbon content, the weld ability is not good. In case of cast iron, because of inherent brittleness of the cast iron and the effect of weld thermal cycle on the metallurgical structure of the cast iron, it is difficult to be welded. The weld ability of cast iron with more than $0,2 \%$ carbon is usually considered to be poor. Hence, gray cast iron with more than $0.3 \%$ carbon are difficult to weld and many steel suppliers will actually 
recommend against welding( Welding of Tool Steel).(AlexanderGrant Paleocrassas, 2005).

Grey Cast Iron, Carbon is present asGraphite flakes distributed throughout, when it is fractured, the exposed surface of metal has gray appearance, and this dispersion of Graphite flakes provides good internal, lubricating property hence excellent machinability and vibration damping characteristics. It has poor tensile strength and ductility, It posses good compressive strength, wear resistance and corrosion resistance, Commonly used for machine bodies, engine blocks, pumps and motor housings, etc.( Hidetoshi Fujii, 2009).

\subsection{Statement of the Problem}

Most automobile components are manufactured from cast iron materials. Gray cast irons lack ductility because of the flake form graphite. This type of cast iron is named from the gray appearance of a fractured surface. In case of cast iron, because of inherent brittleness of the cast iron and the effect of weld thermal cycle on the metallurgical structure of the cast iron, undesirable metallurgical changes in the heataffected zone it is difficult to be welded.

\subsection{Scope of the Paper}

-Conducting the experiment using Arc and TIG Welding process.

-Identity the impact of alloying elements, combinations of base material and filler materials, amount heat for welding of gray cast iron.

\section{Objective}

Investigate the important factors governing Weld ability of gray cast iron and develop improving methods.

\section{Specific Objective}

-investigate welded ability of grey cast iron Improve and -identify the important factors governing weld ability of gray cast iron. Such as influence of alloying elements, combinations of base material and filler materials and edge preparation for welding and to develop weld ability improvement methods and increasing productivity of automobile industry.

\section{Methodology}

\subsection{Experimental Procedure}

In this study, $3 \mathrm{~mm}$ thick commercial gray cast iron plates were successfully applied for arc welded at a temperature lower than the melting temperature of the base metal. The optimized welding parameter was determined by comparing the mechanical properties of the joints obtained under different welding conditions. Also, the differences welding variables of gray cast iron were investigated and discussed by comparing the pervious results. Gray cast iron samples of size $250 \mathrm{~mm} \times 250 \mathrm{~mm} \times 3 \mathrm{~mm}$ were obtained Stringer or weave techniques can be used in depositing the weld bead, though weaving should be kept to within three times the electrode core diameter. For Manual metal arc welding was employed to join the gray cast iron plates. The welding current of 430-870 A, A.C/Dc, with a root gap of 1.5-3.5 mm was used in order to obtain a good weld penetration. Nickel and Nickel-iron type's electrode without preheating and, Cast iron and steel electrodes must be used withoutand with high preheats $\left(530^{\circ} \mathrm{C}\right)$ temperatures. Figure shows the joint design (Fig. 1 a) and electrode angle of $70^{\circ}$ with respect to the top surface of the plates (Fig. $1 \mathrm{~b}$ ). The welding speed used for the unpreheated and preheated pieces with a $58 \%$ Nickel and Nickel-iron and Cast iron and steel electrodes was $17 \mathrm{~cm} / \mathrm{min}$ and $23 \mathrm{~cm} / \mathrm{min}$ respectively, and the speed for the $98 \% \mathrm{Ni}$ was $19.2 \mathrm{~cm} / \mathrm{min}$ and $15.6 \mathrm{~cm} / \mathrm{min}$ respectively. In order to establish the effects of preheating and annealing treatments, three types of welding were performed. In the first case the plates to be joined were preheated at $350{ }^{\circ} \mathrm{C}$ and joined. In the second case, the plates were joined.

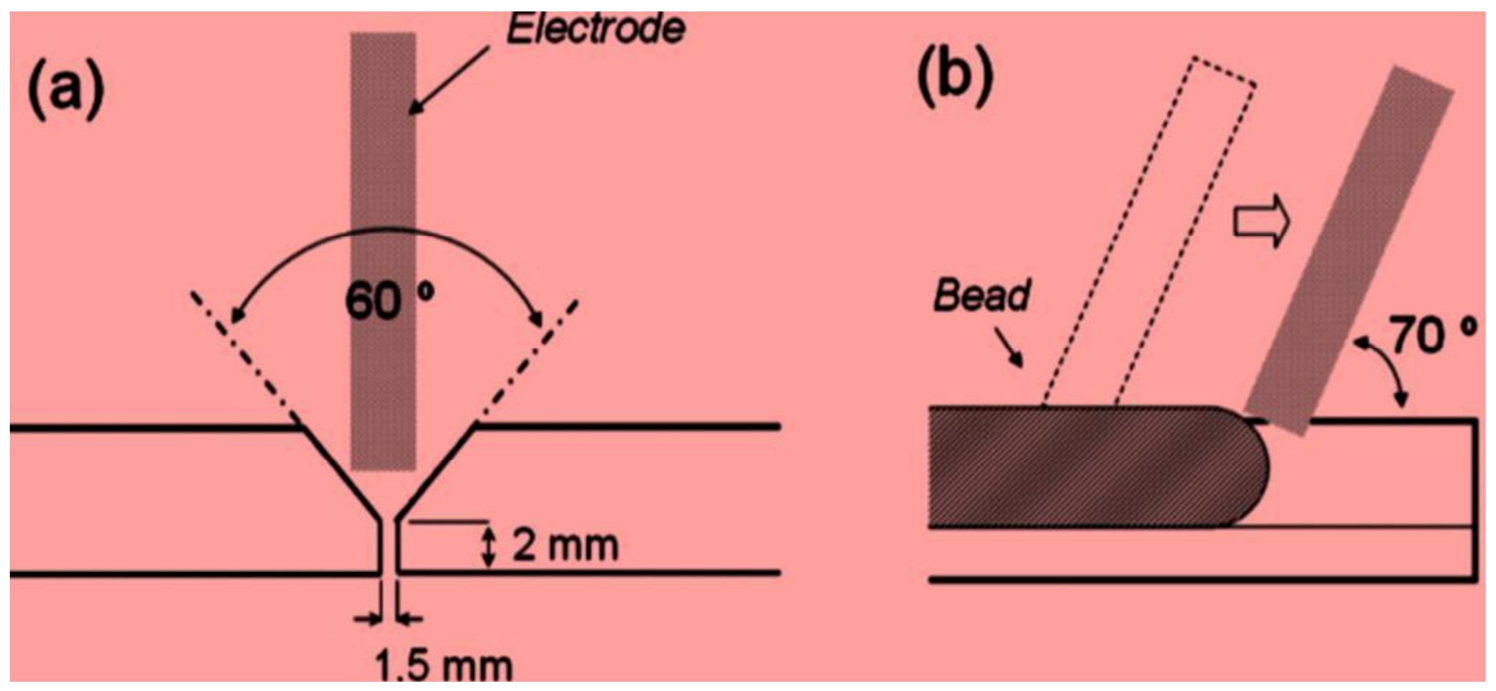

Figure 1. Joint design and position of electrode. (a) Joint design. (b) Electrode's angle and bead's scheme viewed from the front of the bead. 


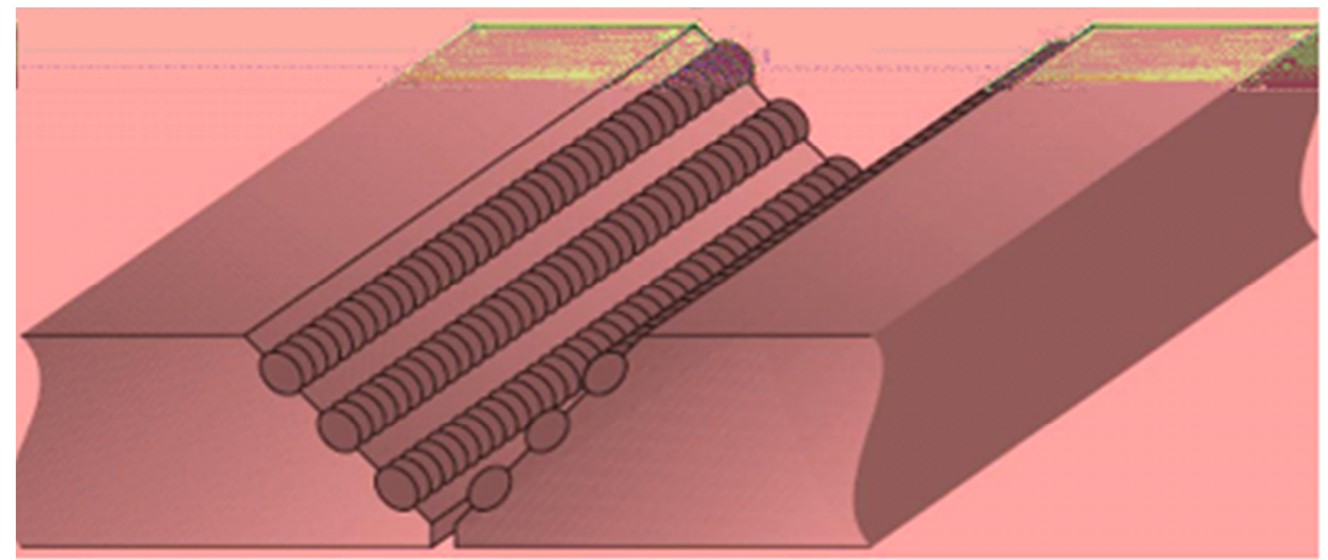

Figure 1c. Welding bead deposition.

Without preheating and post heating. In the third case, the plates joined without preheating were annealed at $870{ }^{\circ} \mathrm{C}$ for $60 \mathrm{~min}$. Samples were prepared from all as-welded and treated plates by cutting it at its centers and polished as well as etched using standard metallurgical procedure. Photomicrographs were taken to analyze the microstructures atvariouszones.Microhardnessvalueswereobtainedonthreedist inguishedregionssuchasweld metal, fusion zone or melt region and heat affectedzone(HAZ)usingauniversalmaterial tester, under a load of $20 \mathrm{KN}$. Yield and ultimate tensile strengths ofall welded plateswereevaluatedby universaltensile testingmachineata constantcrosshead speedof $1 \mathrm{~mm} / \mathrm{min}$.Both hardness and strength values obtained are presented in table 1

\subsection{Experimental Results}

The influence of thermal treatments on Weldability of Gray cast iron and comparison of weld quality obtained using a low priced $\mathrm{Fe}-\mathrm{Ni}$ electrode with that obtained using a pure $\mathrm{Ni}$ electrode were carried Out in order to improve the mechanical properties of welded joints.

Those thermal treatments would result in: (I) relieving residual stress, (II) diminishing the cooling rate and (III) increasing the fluidity and diffusion of the molten material.

\subsection{Ni and Fe-Ni Electrode Results}

Figure 2 a shows a photomicrograph of the as welded weld joint obtained with a $57.2 \%$ Nickel electrode without preheating and cooled in air. Three regions are shown clearly in the figure. The HAZ is observedto be a nodular ferrite pearlitic structure (dark matrix) very similar to the parent metal structure. The dispersed dark flakes correspond to graphite concentrations and had hardness of $380 \mathrm{HV}$. The hardness of the parent metal is found to be $320 \mathrm{HV}$. The MR contains an acicular structure or needle like structure having hardness of $618 \mathrm{HV}$ (268\% higher than that of the parent material). It also has some smaller graphite flakes. From the tensile test, cracks were observed in MR which could be due to its higher fragile character. It is clear from the figure that weld metal contains a brilliant matrix of nickel containing smaller graphite sphere lites compared with that in the parent metal and has hardness value of $210 \mathrm{HV}$.

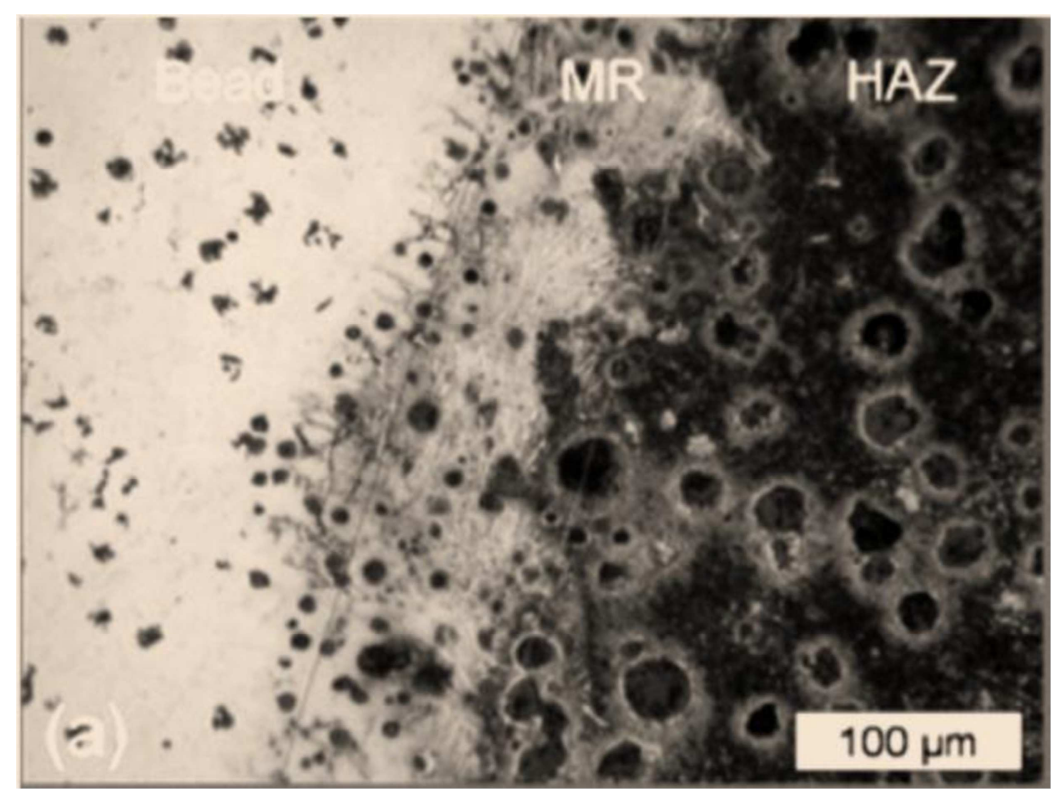

Figure 2a. Optical photomicrographs of theweld joint welded and treated at different conditions: (a) as-welded with $58 \%$ Ni-Fe electrode. 


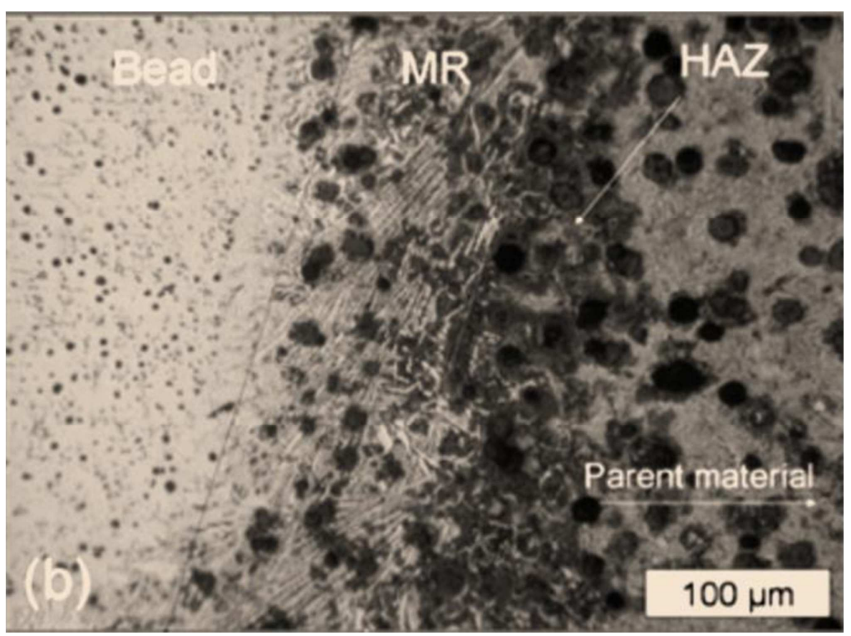

Figure 2b. Optical photomicrographs of theweld joint welded and treated at different conditions: (b) as-welded with $98 \%$ Ni electrode.

Figure $2 \mathrm{~b}$ shows a typicalmicrostructure of the weld joint welded with a $98 \% \mathrm{Ni}$ electrode without preheating. From the figure it is found that the HAZ is visually darker due to less amount of ferriticmatrix structure resulting from the dissolution of ferrite in nickel. The hardness of HAZ was found to be $330 \mathrm{HV}(143 \%$ higher than that of parent metal) and was very close to the hardness value of HAZ obtained using $\mathrm{Fe}-\mathrm{Ni}$ electrodes. From the figure it is found that the MR contains several long needles acicular structures (ferriticpearlitic structures) combined with some small needle acicular structures (marten site). It was found that the amount of marten site present was lesser than that was present in MR of previous weld joint obtained using Fe-Ni electrode which was also confirmed with its corresponding hardness value of
$480 \mathrm{HV}$. From the figure it is found that the weld bead contains ferritic-pearlitic structure with a high concentration of small graphite flakes distributed uniformly in the matrix resulting due to the dissolution of graphite in nickel. From table I it is found that the weld metal hardness value is less. Though the bead had higher ductility due to the uniform distribution of graphite flakes fragile fracture cracks were observed in the MR which would be due to the higher hardness value of marten site present.

\subsection{Effects of Preheating}

A minimum preheat of $200^{\circ} \mathrm{C}$ is recommended, but $315^{\circ} \mathrm{C}$ is generally used.

Table 1. Mechanical, Thermal Property of Materials and the effect of Heat treatment.

\begin{tabular}{|c|c|c|c|c|c|c|c|c|}
\hline Type of & Electrode type & Ultimate & Yield & $\%$ & Har & f weld joint & Place of & \\
\hline treatment & & $\begin{array}{l}\text { tensile } \\
\text { strength } \\
\text { (Mpa) }\end{array}$ & $\begin{array}{l}\text { limit } \\
(\mathrm{Mpa})\end{array}$ & elongation & MR & Bead & HAZ & Failure \\
\hline No pre & $\mathrm{Fe}-\mathrm{Ni}$ & 520 & 460 & 8 & 618 & 210 & 360 & MR \\
\hline heating & $98 \% \mathrm{Fe}-\mathrm{Ni}$ & 400 & 360 & 11 & 480 & 180 & 330 & MR \\
\hline 350 pre & $\mathrm{Fe}-\mathrm{Ni}$ & 480 & 410 & 12 & 330 & 180 & 240 & MR \\
\hline 870 pre & $\mathrm{Fe}-\mathrm{Ni}$ & 420 & 350 & 15 & 260 & 183 & 187 & Bead region \\
\hline heating & $98 \% \mathrm{Fe}-\mathrm{Ni}$ & 398 & 350 & 16 & 250 & 175 & 180 & Bead region \\
\hline Without & $\begin{array}{l}\text { Cast iron } \\
\text { Electrode }\end{array}$ & - & 475 & 335 & 7 & - & 230 & - \\
\hline
\end{tabular}

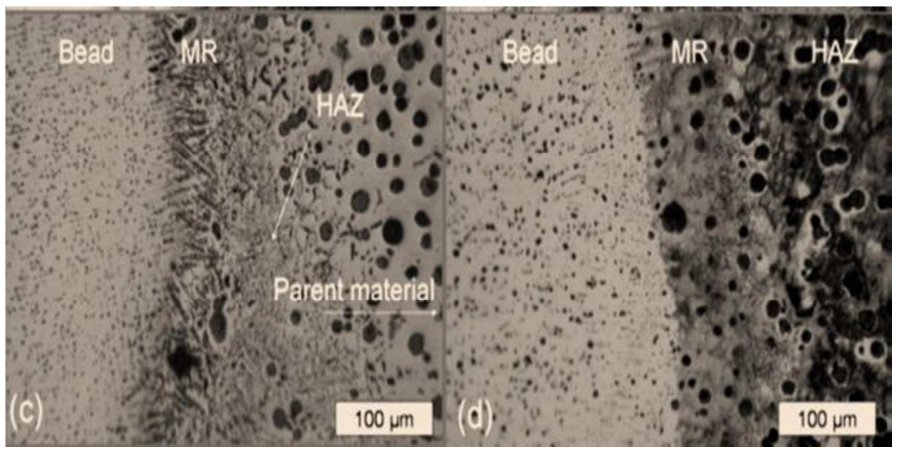

Figure 2c. Optical photomicrographs of theweld joint welded and treated at different conditions :(c) preheated and as-welded with $58 \%$ Ni-Fe electrode (d) welded with $98 \%$ Ni-electrode and annealed. 
From table I it is evident that when thermal treatments were performed, the elongation is increased and hardness is decreased in all regions irrespective of the type of electrode used. Figure $2 \mathrm{c}$ ) shows a photomicrograph of the weld bead obtained with $58 \% \mathrm{Ni}$ electrode at preheated condition. Thebrilliant metallic matrix observed in the HAZ and in the parent material, indicates the dissolution of graphite in nickel. An open pearlitic structure inside an austenitic matrix grew in that region. Nevertheless, graphite in the HAZ was dissolved and small dots were observed instead of flake structures. The width of the MR is also decreased due to nickel contribution and its structure is found to be a pearlitic structure in the austenitic matrix. A laminar structure was observed at higher magnification. The (weld metal) bead region has smaller spheroidal graphite than that of parent material. Hardness obtained in the HAZ was 249 HV, very similar to the hardness value of the parent material.

The ductility was increased twice and the rest of values were very similar. The mode of failure observed from tensile test was found to be ductile in the bead. Figure 2 d) shows the typical microstructure of a welded cast iron using a $98 \%$ $\mathrm{Ni}$ electrode at preheated condition. It is observed that the concentration of pearlitic structure in MR is decreased. Graphite in form of smaller spherolytes grew in the bead region and got distributed uniformly. This decreasing of the pearlitic structure concentration and the smaller spherolyte forms maybe due to nickel metal, which absorbs carbon, dissolving it in its metallic matrix From table I it is found that the ductility is increased to $14 \%$ and hardness diminished. It is also found that the yield limit is not affected significantly.

\subsection{Post Heating Results}

Marten site in the HAZ may be tempered to a lower strength or a more ductile structure during post weld heat treatment, or it may be totally eliminated by ensuring very slow cooling rates after welding. An Optimum Aluminum Addition exhibits substantial graphitization and reduced hardness.

\section{Conclusions}

Gray cast iron plates were welded using two different electrodes at three different conditions and its effects were analyzed. The following conclusions were arrived at:

-High purity Nickel electrodes showed a better Weldability from enhanced ductility due to lower acicular structures formed and better uniform distribution of graphite in the bead. These electrodes have been used with or without preheating and/or post weld heat treatment.

-Cast iron electrodes also showed a better Weldability.-The preheating treatment increases the ductility of the welded piece through minimizing hard and fragile microstructures and improves Weldability of gray cast iron. -A post heat treatment can be substituted for the preheating treatment which also improves the ductility of the base metal.

\section{Acknowledgements}

I would like to thanks very much for Aram ${ }^{1}$, Levon Aghasyan $^{1}$, Yeghiasaryan ${ }^{2}$, Silva Amiryan ${ }^{2,{ }^{* 1}}$ Institute of Zoology of National Academy of Sciences of Armenia, Yerevan, Armenia ${ }^{2}$ Yerevan State University, Yerevan, Armenia, detail and wonderful reviewing and amazing feedback of the paper to increases scientific acceptance and strength of the paper. The author also wishes to thank the support from the sciencepublishinggroup.com $/ \mathrm{j} / \mathrm{sr}$ under grants ISSN: 2329-0935 (Print); ISSN: 2329-0927 (Online).

\section{References}

[1] Kita-Shinagawa, 2011, Arc Welding of Specific Steels and Cast Irons).

[2] TALAT Lecture 4202, Weld ability of Metals.

[3] Hidetoshi Fujii, 2009, Investigation of welding parameter dependent microstructure and mechanical properties in friction stir welded pure Ti joints.

[4] ErhiZahaniBintiBuyong, The Investigation of MIG Welding Paramete Effects on Welding of dissimilar Metal(Stainless Steel to Cast Iron)

[5] By J. H. Devletian, Gray Iron Weld Metal Containing

[6] Alexander Grant Paleocrassas ,2005, Feasibility Investigation Of Laser Welding Aluminum Alloy 7075-T6 Through The Use Of A $300 \mathrm{~W}$,

[7] By Samuel D. Kiser, 2005, Welding Cast Iron: Straightforward

[8] Bhavikatti S.S., 2012, Investigation for Hardening of Cast Iron using Low Power Fibber Laser.

[9] Kita-Shinagawa, 2011, Arc Welding of Specific Steels and Cast Irons

[10] MUSTAFA AYGÜL.2012, Fatigue Analysis of Welded Structures Using the Finite Element Method

[11] ErhiZahaniBinti, The Investigation of MIG Welding Parameter Effects on Welding of dissimilar Metal (Stainless Steel to Cast Iron).

[12] UTP Schweissmaterial, welding of cast iron materials.

[13] Bipin Kumar Srivastava 2010, A Review On Effect Of Preheating And/Or Post Weld Heat Treatmemt (Pwht) On Mechanical Behaviour Of Ferrous Metals.

[14] Gary J. Reed, Understanding cast iron and repairing damaged castings permanently

[15] Janina M. Radzikowska, Metallography and Microstructures of Cast Iron.

[16] International Association of Classification Societies, Requirements Concerning Materials And Welding. 